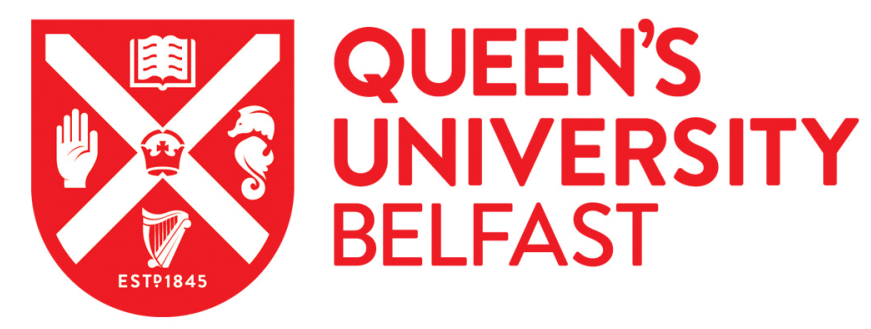

\title{
Optimal outcomes and women's positive pregnancy experience: a comparison between the World Health Organization guideline and recommendations in European national antenatal care guidelines
}

lannuzzi, L., Branchini, L., Clausen, J. A., Ruiz-Berdun, D., Gillen, P., Healy, M., Beeckman, K.,

Siejmonsbergen-Schermers, A., Escuriet Peiro, R., Morano, S., DI Tommaso, M., \& Downe, S. (2018). Optimal outcomes and women's positive pregnancy experience: a comparison between the World Health Organization guideline and recommendations in European national antenatal care guidelines. Minerva Ginecologica, 70(6), 650-662. https://doi.org/10.23736/S0026-4784.18.04301-0

Published in:

Minerva Ginecologica

Document Version:

Peer reviewed version

Queen's University Belfast - Research Portal:

Link to publication record in Queen's University Belfast Research Portal

Publisher rights

(C) 2018 Edizioni Minerva Medica.

This work is made available online in accordance with the publisher's policies. Please refer to any applicable terms of use of the publisher.

\section{General rights}

Copyright for the publications made accessible via the Queen's University Belfast Research Portal is retained by the author(s) and / or other copyright owners and it is a condition of accessing these publications that users recognise and abide by the legal requirements associated with these rights.

\section{Take down policy}

The Research Portal is Queen's institutional repository that provides access to Queen's research output. Every effort has been made to ensure that content in the Research Portal does not infringe any person's rights, or applicable UK laws. If you discover content in the Research Portal that you believe breaches copyright or violates any law, please contact openaccess@qub.ac.uk. 
Optimal outcomes and women's positive pregnancy experience: a comparison between the World Health Organization guideline and recommendations in European national antenatal care guidelines

Laura IANNUZZI ${ }^{1}$, Lucia BRANCHINI ${ }^{2}$, Jette A. CLAUSEN ${ }^{3}$, Dolores RUIZ-BERDÚN ${ }^{4}$, Patricia GILLEN $^{5}$, Maria HEALY ${ }^{6}$, Katrien BEECKMAN ${ }^{7}$, Anna SEIJMONSBERGEN-SCHERMERS $^{8}$, Ramon ESCURIET PEIRÓ ${ }^{9}$, Sandra MORANO ${ }^{10}$, Mariarosaria DI TOMMASO ${ }^{11}$, Soo DOWNE ${ }^{12}$

${ }^{1}$ Physiological Pregnancy Pathway and Margherita Birth Centre, Department of Health Care Professions, Careggi University Hospital, Florence, Italy; ${ }^{2}$ MondoDonna Onlus, Association for support and Integration of Immigrant Populations and Vulnerable Women, Bologna, Italy; ${ }^{3}$ Department of Midwifery, University College Copenhagen, Copenhagen, Denmark; ${ }^{4}$ History of Science, Department of Surgery, Medical and Social Sciences, Universidad de Alcalá, Alcalá de Henares, Spain; ${ }^{5}$ Southern Health and Social Care Trust, Northern Ireland and School of Nursing, Institute of Nursing and Health Research, Ulster University, Newtownabbey; ${ }^{6}$ School of Nursing and Midwifery, Queen's University Belfast, Belfast, Northern Ireland; ${ }^{7}$ Nursing and Midwifery Research unit, Faculty of Medicine and Pharmacy Vrije Universiteit Brussel, Belgium; ${ }^{8}$ Department of Midwifery Science, AVAG, Amsterdam Public Health Research Institute, Amsterdam UMC, VUmc, Amsterdam, the Netherlands; ${ }^{9}$ Catalan Health Service, Generalitat de Catalunya. Barcelona, Spain; ${ }^{10}$ Department of Neuroscience, Rehabilitation, Ophthalmology, Genetics and MaternalInfant Sciences (DINOGMI), University of Genoa, Genoa, Italy; ${ }^{11}$ Department of Science for Woman and Child Health, University of Florence, Florence, Italy; ${ }^{12}$ Research in Childbirth and Health Unit (ReaCH), School of Community Health and Midwifery, University of Central Lancashire, Preston, United Kingdom.

\section{Corresponding author:}

Laura Iannuzzi, PhD, MSc, PgCert, BMid, RM,

Lead Midwife, Physiological Pregnancy Pathway and Margherita Birth Centre, Department of Health Care Professions, Careggi University Hospital, Largo Brambilla 3, 50134 Florence, Italy

Contact email: iannuzzil@aou-careggi.toscana.it; lauraiannuzzi@gmail.com 


\begin{abstract}
BACKGROUND: The publication of the World Health Organization (WHO) recommendations on antenatal care in 2016 introduced the perspective of women as a necessary component of clinical guidelines in maternity care. WHO highlights the crucial role played by evidence-based recommendations in promoting and supporting normal birth processes and a positive experience of pregnancy. This paper aims to explore and critically appraise recommendations of national antenatal care guidelines across European countries in comparison with the WHO guideline.
\end{abstract}

METHODS: We collected guidelines from country partners of the EU COST Action IS1405. Components of the documents structure and main recommendations within and between them were compared and contrasted with the WHO guideline on antenatal care with a particular interest in exploring whether and how women's experience were included in the recommendations.

RESULTS: Eight out of eleven countries had a single national guideline on antenatal care while three countries did not. National guidelines mostly focused on care of healthy women with a straightforward pregnancy. The level of concordance between the national and the WHO recommendations varied along a continuum from almost total concordance to almost total dissonance. Women's views and experiences were accounted for in some guidelines, but mostly not placed at the same level of importance as clinical items.

CONCLUSIONS: Findings outline convergences and divergences with the WHO recommendations. They highlight the need for considering women's views more in the development of evidence-based recommendations and in practice for positive impacts on perinatal health at a global level, and on the experiences of each family.

\title{
KEYWORDS
}

Antenatal care, prenatal care, guideline, women's experience, pregnancy, midwifery, World Health Organisation 


\section{TEXT}

\section{Introduction}

Historically, pregnant women have sought help from members of the local community with skills and experience in maternity care. An important component of this kind of care seemed to be the recognition of the need to 'mother the mother' as well as to ensure that she and her baby were healthy, physically and emotionally, as pregnancy progressed. With the development of modern medicine, there has been a shift away from the psychosocial and community supportive aspects of pregnancy, and towards a greater focus on monitoring and surveillance by professional experts (doctors and midwives) ${ }^{1}$. Throughout the 20th century, hundreds of pregnancy advice books have been written by doctors, midwives, nurses, and institutional authors ${ }^{2}$. However, there is a lack of consistency to this advice between the various publications, and they are not always based on the latest scientific discoveries ${ }^{3}$. This has also been the case in texts written for medical students, obstetric trainees, obstetric nurses and midwives ${ }^{4}$. In relation to the wider health care field, this is the context in which the Evidence Based Medicine movement emerged in the late 20th century ${ }^{5}$.

As for health care in general in many societies, beliefs about the appropriate antenatal care (ANC) provider has shifted from known community members with extensive experiential knowledge, to experts with formal professional qualifications, often based in a central location (health centre or hospital) at some distance from women's homes. There is now general acceptance in many societies and governments that pregnant women benefit from such professional input during the antenatal period. However, as the responsibility for ANC has shifted from lay community members with experience to professional care providers with qualifications, the emphasis of ANC has shifted towards a primary role in measuring and monitoring, and away from tending and befriending. This has meant that some (particularly marginalised) women and communities do not use ANC, partly because of distance and lack of resources to travel, partly because of experiences of being mistreated by professional care providers, and partly because ANC does not provide the psychosocial care they want and need ${ }^{6,7}$.

In recognition of these issues, and to address the question about how many ANC visits are optimal, the World Health Organization (WHO) undertook a review of the evidence on ANC provision, and, as a result, published new guidelines in $2016^{8}$. WHO recognised that previous guidelines used systematic reviews of RCTs as the basis for the guideline production. The topics investigated in the underpinning RCTs for systematic reviews, and the outcomes used for them, tend to reflect what is seen to be important by clinicians and researchers (e.g. tests, treatments and identification of pathology). The WHO team realised that this did not necessarily reflect the full scope of what women want and need in the antenatal period ${ }^{9}$. For this reason, the WHO team undertook an $a$ 
priori scoping review of the worldwide qualitative literature on 'what matters to women in pregnancy', as the basis both for the outcomes measured used in the guideline, and as a guide for some of the interventions assessed ${ }^{10}$.

The WHO review found that what mattered to women was a combination of social support, timely information, and clinical care. Women thought about pregnancy as part of the journey to motherhood, and not as a standalone period of time. They also valued respectful, compassionate care tailored to their needs. As a result, the new WHO guidelines included both a new outcome of 'positive pregnancy experience', and reviews of interventions to support this.

The guideline also changed previous advice on the minimum number of ANC visits, from four to eight. Recognising that a 'visit' should be more than, for example, an ultrasound scan or a series of tests, but that it should be a human encounter, the guideline also changed the term from 'visit' to 'contact'. A range of other clinical practices and recommendations were also updated in the new version.

There is a dearth of research concerning how far global guidelines are adopted at the national level around the world, and whether significant differences in recommendations exist between countries. Difficulties in applying some recommendations can be due to several factors, including the presence of different social context, health care systems and funding mechanisms, as well as professionals' resistance to change the way they have been working for years. This paper offers an original contribution by presenting the first multinational review of the similarities and differences in the content of national ANC guidelines in eight European countries in relation to their national health contexts. Comparisons are made both with the 2016 WHO guideline, and between each contributing country.

The study reported in the paper aimed to compare, explore and critically appraise the provision, approach and recommendations of national guidelines on ANC in relation to the 2016 WHO ANC guidelines, with a particular emphasis on whether and how women's views and experiences were incorporated in the national guidelines.

\section{Material and methods}

This was a multinational comparative mapping study. A call for participation was circulated amongst members of European partner countries involved in EU funded COST Action IS 1405, and in particular to members of the action working group that is researching the impact of organizational elements on intrapartum interventions ${ }^{11}$. The COST Action IS 1405 includes over 
120 scientists, academics, clinicians, policy makers, service users and activists from 33 countries, all working in the area of maternity care.

Initially, eight countries declared their willingness to contribute; subsequently members of three other East European countries were directly contacted by a co-author (JC) and provided additional data and insights on the topic.

A data collection tool was created and revised by the group prior to starting data collection. The agreed tool consisted of an $\mathrm{Excel}^{\odot}$ worksheet where specific questions about existing national guidelines on ANC were posed, including:

- Country of origin

- Presence of a national guideline on ANC produced by the country health authorities

- Presence of national guidelines on ANC issued by professional associations of obstetricians and/or midwives

- National guideline title, authors, year of publication, main reference

- Level of inclusion of recommendations reported on WHO guideline

- Presence of clinical and non-clinical recommendations in the national document

The tool then provided a list, in columns, of the main recommendations included in the WHO guideline (a recommendation per column) so that the items could be used to compare and contrast with what was reported in each country's guideline.

To assess the level of correspondence with the WHO guidelines, the recommendations in national guidelines where coded as: "1-Present, completely aligned" (if the recommendation was present and agreed with WHO completely), "2-Present, partially aligned" (if the recommendation was present and agreed with WHO to an extent), "3-Present, non-aligned" (if the recommendation was present but disagreed with WHO), or "4-Absent” (if the recommendation was not mentioned at all) (see Figure 1).

Informants were requested to provide the full original document (and, where available, its English version) and, in case of absence of a national guideline, to share their reflections on the phenomenon and give some contextual information. The data were collected between June and July 2018.

A narrative descriptive analysis was performed after the completion of data collection in July 2018. The aim of the analysis was not to appraise the quality of the recommendations provided, but only to compare the main items and discourses reported in the documents with a particular interest on investigating whether or not and how women's experiences were included in the reports.

\section{Results}




\section{Main characteristics of the guidelines}

Table one presents the key characteristics of the included guidelines. Of the 11 participating countries, eight (Italy, Spain, Northern Ireland, United Kingdom, France, Denmark, Belgium, Republic of Macedonia) reported an official national guideline on $\mathrm{ANC}^{12-18}$. Two (Croatia and Slovakia) declared no national guideline on the topic in their own countries, and in one country (the Netherlands) too many national level guidelines ${ }^{19-21}$ were available to be described. Although Northern Ireland is part of United Kingdom (UK) it developed a specific Antenatal Care Pathway, based on the NICE guidelines, to assist with the implementation of care at local level. The researchers thought that Northern Ireland recommendations could be examined separately, highlighting them as an example of how national guidelines may be operationalised locally.

In Croatia and Slovakia there is a total absence of any national guidelines concerning care in pregnancy, whether edited by health care authorities or by national professional bodies/associations. In the Netherlands, many nationally agreed guidelines are present, with separate guidelines for topics such as the recommended antenatal visit schedule, smoking, blood loss, and anaemia in pregnancy. For some topics, there are different evidence-based guidelines written by different associations. There is no single evidence-based document that summarizes all these guidelines and that has been approved by the different associations.

All the eight guidelines examined in detail were produced by national health authorities. In each case, their working groups/editorial boards included a number of representatives from the main national colleges and/or associations of midwives and gynaecologists-obstetricians and/or physicians. Three of the eight (United Kingdom, Denmark, Spain) also included user representatives.

Most of the countries (Italy, Spain, Republic of Macedonia, Belgium, Northern Ireland) have guidelines that represented an adaptation to, or included as main reference, the NICE guideline on 'Antenatal Care: routine care for the healthy pregnant women' ${ }^{15}$. The Belgian guidelines were also based on the Australian guideline on antenatal care ${ }^{22}$, while Northern Ireland used as additional resource the NICE 'Schedule of appointments for antenatal care ${ }^{23}$. The Danish ${ }^{17}$ guideline did not support recommendations with any references; no explanation for this choice was provided in the document.

The majority of the European guidelines considered were published prior to the dissemination of the WHO 2016 ANC guidelines. Two were produced in 2016. The NICE guideline ${ }^{15}$ was originally published in 2008 and later updated in 2017 after the publication of WHO (Table I).

The WHO guideline is the only one that highlights from its title the purpose of achieving positive pregnancy experience. The diverse titles used for the guidelines seemed to reflect cross-national 
similarities and differences in culture and perspective. For instance, Italy and UK presented their work as the ANC pathway for "healthy women" or "physiological pregnancy" highlighting pregnancy as a physiological and normal process, The French guideline, instead, introduced the guideline as a tool to identify and prevent 'risk'. This seems to reflect a dominating 'risk-culture' around pregnancy that was also illuminated by the choice of the title of the Belgian guideline. The Macedonian "Guideline for Medical Care during Antenatal Care under the Law of Health Protection" focuses on clinical aspects, in a setting where health care in general is very medically focused. The other countries appeared to have adopted a more neutral language (i.e. "Pregnancy and Postnatal Care Guidelines" in Spain or "Core Pathway for Antenatal care” in Northern Ireland).

The national guidelines were mostly focused on a population of physiological/low-risk/healthy pregnant women. Interestingly, only four of the documents (UK, Spanish, Danish, and French) provided a clear definition of 'healthy' mother or uncomplicated/ physiological pregnancy. France, Spain and UK, included a list of criteria for definition of low-risk pregnancy, while the Danish guideline proposed four levels of ANC developed for women with different risk profiles, so that women could be signposted to the appropriate pathway of care.

\section{Comparison of recommendations}

The WHO guidelines focused on clinical, educational, and organizational aspects of care, providing a total of 49 recommendations. As shown in Table II, the main items of interest for WHO related to nutritional interventions; maternal assessment; fetal assessment; preventive measures; interventions for common physiological symptoms and health systems interventions to improve the utilization and quality of ANC. The presence of non-clinical recommendations (such as information, the legal framework, or organization of care) also characterised most of the national guidelines. Spain and Belgium were the exception, where the focus was solely on clinical aspects.

The level of similarity between WHO recommendations and those included in the European guidelines varied between countries. The national guidelines that had the highest level of total adherence with WHO recommendations were those from UK and Italy (19/49) followed by Northern Ireland (15/49), Spain (13/49) and Denmark (12/49). France, Belgium and the Republic of Macedonia were the least likely to reflect WHO recommendations (5/49). There was only one area of universal agreement; this was the specific recommendation on the adoption of HIV test as screening means for all pregnant women. In contrast, 18 recommendations made by WHO were not mentioned in any of the European guidelines.

In most cases (12/18), this absence regarded nutritional or preventive recommendations. Most of these were specific to more particular contexts such as care of undernourished, disadvantaged populations living in condition of deprivation, and/or zones with higher incidence of diseases (e.g. 
severe anaemia or malaria) most often present in low-income countries. Another set of WHO recommendations that was almost absent (4/18) in the national guidelines broadly included health systems interventions to improve the utilization and quality of ANC. This encompassed community-based interventions to improve communication and support, task shifting components of ANC delivery, and recruitment and retention of staff in rural and remote areas.

National guidelines generally agreed on recommendations to offer women counselling on nutrition and physical activity to promote healthy behaviours and prevent excessive weight gain and the use of iron and folic acid in pregnancy. However, recommendations on these supplementations were inconsistent between countries. Indeed, while WHO recommended the daily intake of both iron and folic acid supplementation in pregnancy, only supplementation with folic acid appeared universally in national guidelines (except for the Belgian guidelines, in which folic acid was not mentioned). However, even within this level of agreement, there were cross-country differences in timing, dosage and even scope. The rationale in the WHO document included prevention of maternal anaemia, puerperal sepsis, low birth weight, and preterm birth. The UK, Northern Ireland, French and Italian guidelines focused more on the prevention of fetal/neonatal malformation, such as spina bifida.

The WHO guideline includes a recommendation against the use of multiple micronutrient supplementation. Only the Spanish national guideline mentioned multivitamins, and recommended against their use.

As regards maternal and fetal assessment recommendations, the European guidelines mostly reflected the WHO guidelines. Almost all countries agreed on recommending full blood count testing for diagnosing anaemia, the use of midstream urine culture for diagnosing symptomatic bacteria, asking during the encounters with women in pregnancy about smoking habits, use of substances and the particularly sensitive and impactful topic of intimate/domestic violence. Belgium and Denmark were the countries less reflective of WHO recommendations; Belgium because it did not include these items in its guideline, while Denmark differentiated mostly for the contents, generally recommending specific tests only in case of signs and symptoms rather than as mandatory in ANC. Ambiguous messages were found as concerns the detection of hyperglycaemia and screening/classification of gestational diabetes mellitus (GDM) in ANC. National guidelines often included glucose test as part of prenatal care but, similarly to WHO, they did not recommend universal screening for GDM, preferring that the decision is made based on individual risk factors or health conditions. The timing and criteria recommended for performing glucose tests differed at times between countries.

All guidelines stressed the importance of women's perception, education and counselling on fetal movements in pregnancy, and almost all (except for Spain and France, that did not mention this 
issue) agreed with WHO in recommending that daily count/use kick count charts should not be performed as routine practice. Moreover, WHO recommended that practitioners should not replace abdominal palpation with symphysis-fundal height (SFH) measurement for the assessment of fetal growth. No discussion of this issue was found in the European guidelines. SFH was universally recommended in national guidelines, with or without mentioning the alongside use of abdominal palpation, as part of the antenatal assessment for fetal growth generally starting from 24 weeks of gestational age. Excluding France and Belgium who did not include this topic, all countries concurred in actively not recommending the routine use of antenatal cardiotocography and doppler ultrasound examination for improving perinatal outcomes.

Discrepancies emerged on the use and number of ultrasound scans recommended during pregnancy. The WHO guidelines were the only ones to recommended just one routine early scan for fetal assessment purposes. The other countries mainly indicated two scans to be performed: one in the first trimester (early pregnancy) to check for gestational age, the number of embryos, and any structural anomalies; and the other in the second trimester, mainly to assess fetal anomaly. French and Belgian guidelines recommended the highest number, of three (one per trimester).

The WHO guideline offers a number of indications on "Intervention for common physiological symptoms". The most common recommendations in national guidelines relates to the use of nonpharmacological options for varicose veins and oedema (included by Italy, France, UK, Macedonia, and Northern Ireland), dietary modification fibre supplements for constipation if needed (in Italy, France, UK, Macedonia) and postural exercises and other non-pharmacological treatment options for low back pain (in Italy, Spain, Macedonia and Northern Ireland). Unlike the WHO guideline, recommendations on treatments for leg cramps were universally absent in the included European guidelines.

National guidelines included recommendations in the area of health services to improve the use and quality of ANC, but with some differences with the recommendations in the WHO document. European countries fundamentally agreed with WHO in recommending the utilisation of womanheld case-notes. Variations between countries and WHO related mostly to the recognised owner of this aid. The woman herself was seen as the main owner and carrier of the notes on her health throughout her ANC pathway in the UK, Northern Ireland, France and Denmark guidelines; while in Italy and Macedonia both women and their lead professional carers appeared to be shared casenotes holders. In Spain recommendations mentioned the use of a computerised clinical record where information can be shared between professionals, without mentioning the women's ownership of those records. Belgium did not consider the topic in its guideline. 
Midwife-led continuity of care models, were recommended, in line with WHO, in half of the countries (Italy, Spain, UK, Northern Ireland). This involves women being cared for by a known midwife or a small group of midwives in a continuum throughout antenatal, intrapartum and postnatal period. The theme of midwife-led models was not included in the recommendations from Denmark, Macedonia and Belgium. French guidelines mentioned the possibility of different models of care (i.e. midwife-led, medical-led or shared) when indicating criteria for orienting women to services, but no evident recommendations on the use of midwife-led models. There was most the same level of adherence regarded the recommendations on facilitating participatory women's group at a community level ${ }^{8,12-15}$. Along with WHO, only Italy, Denmark, Northern Ireland and Macedonia mentioned group antenatal care. However, in the WHO guideline, this was a recommendation for a way of organising the total antenatal encounter (clinical, supportive, educational) whereas in the national guidelines it was mostly seen as a way of providing antenatal education only.

All guidelines recommended several periodic 'visits' throughout pregnancy as crucial encounters for ANC. Besides France and Denmark (that were similar to WHO), European guidelines indicated in their recommendations a smaller number of contacts than WHO.

\section{Women's experience and perspective}

The WHO guideline stated the importance of the quality of experience in ANC; indeed, the whole guideline is framed by the notion of ' $a$ positive pregnancy experience'. This gives equal weight to maintaining physical and sociocultural normality/ wellbeing as much as possible; keeping a healthy pregnancy for mother and baby; having an effective transition to positive labour and birth; and achieving positive motherhood (including maternal self-esteem, competence and autonomy) ${ }^{10}$. The importance of maternal experience also emerged in the background text of most of the guidelines considered (Northern Ireland, Belgium, Macedonia, UK, Spain, Denmark and Italy) but the degree to which this was given the same weight as clinical aspects of care in the actual recommendations for practice varied across the guidelines.

In the Italian guidelines, the theme of women's experiences mostly appeared while discussing the evidence in support of recommendations. In particular, authors outlined how birth is an event with high impact on women's lives, and stressed the importance of good communication between women and professional, and of offering antenatal classes programmes and midwife-led models of care in order to support and enhance the quality of women's experience. The latter was mentioned also as an element of maternal and neonatal health, that deserves further qualitative investigation in the national context. 
The Northern Ireland guideline ${ }^{14}$ identified the importance of choice for women and their families and accessibility to midwife-led services if that is the woman's preference. The core pathway for ANC highlighted that, at each contact, the midwife (and the doctor as lead professional, when referral is necessary) is expected to continue to build the relationship with the woman, particularly in the early contact visits, to discuss options for place of birth, including signposting to information on planning birth in midwife-led units ${ }^{24,25}$.

As previously mentioned, in the case of the Spanish guideline, as in some other countries, women belonging to associations involved in an optimal healthcare before, during and after childbirth (such as "Via lactea" [milky way] or "El parto es nuestro" [Birth is ours] were part of the group of guideline authors $^{13}$ (p7). Explicitly, for each Spanish recommendation, four aspects were considered: quality of evidence, benefits/risk balance, cost and resources and women's preferences on the subject. As in the experience of the development of the WHO guideline, however, evidence on women's experiences, values and preferences was not found for several guideline topics. More generally, suggestions included the offer of drafting a birth plan from the 28th week of pregnancy (p30). Subtly, the language of the guideline uses terms like "suggest to women" "inform women" rather than imperatives like "tell women" or "prescribe".

The Danish guideline acknowledged women's experience in general and described the goal for maternity care as being a developmental process from pregnancy to the post-partum period. The text notes that this period should be seen as a coherent natural life process with the possibility of personal development and growth.

In the UK guideline there was no explicit recommendation based on women's experiences. However, the guideline narrative generally stressed the paramount importance of women's choice even when this goes against the healthcare professionals' views. The text highlighted that the guideline is not mandatory, but a 'guide' to inform clinical practice with attention to the clinical situation, and women's needs and preferences.

The focus of the national antenatal care guideline in Belgium was on minimal clinical follow-up in low risk pregnancies. Diet, life-style, behaviour and treatments were not subject of the guideline. With regard to women's experiences, there was no special chapter, section or paragraph on this subject. Only in the margin was there some mention about discussing choices about fetal screening (informed decision making). The Belgian Health Care Knowledge Centre is currently working on a guideline including all these items.

In the Netherlands, among the multiple existing national guidelines, there is one on antenatal midwifery accompaniment that contains discussion of clients' perspectives, including transition to parenthood (psyche, social environment, bodily processes, fear and stress), expectations, satisfaction, and personal desires, and the need for client-centred ANC and individualised care. It also addresses midwives' attitudes, knowledge and communicative skills. This may also be the case 
for the national guidelines of specific professional groups in other included countries, but for the purpose of this review, only their single national multiprofessional guideline was examined.

\section{Areas of interests of European guidelines that WHO does not mention}

The national guidelines reviewed for this paper included a number of topics that were not explicitly recommended in the WHO guideline. These included communication and information in ANC, especially for marginalised and vulnerable women, and those who do not speak the local language (Italy, UK and Northern Ireland). They also included health issues, screening and management of specific pregnancy conditions, including female genital mutilation and breech presentation postdates (Italian, UK, Northern Ireland and Spanish guidelines)

In the Northern Ireland guideline, the benefits of breastfeeding are clearly signposted from the 28 week-contact onwards. The importance of the woman and her partner building a relationship with the baby, including infant wellbeing, is highlighted with reference to the NICE CG $45^{26}$, as is the need for additional assessment if a woman repeatedly ( $\geq$ three times) self refers for professional review outside of normal pattern of ANC visits.

\section{Discussion}

There is almost universal agreement that the provision of high quality care during pregnancy, childbirth, and the early postnatal period is a powerful driver for the health of women, neonates families and societies ${ }^{27}$. However, the nature and content of such care is more debatable. Our survey of European guidelines has included examples from northern, eastern, western and southern Europe, and from countries with a range of population demographics and health system funding mechanisms. It therefore provides a comprehensive overview of the shifting norms across Europe in terms of the nature and content of ANC. The recent WHO antenatal guideline provides a benchmark for this global shift, as it is designed to apply in a wide range of contexts, and it explicitly includes active recommendations for supportive, relationship-building provision, as well as for maternal and fetal observations and nutritional and clinical care. As this mapping survey has shown, in many (but not all) national guideline documents for antenatal care, there has been a shift in the rhetoric about the need for care to be woman centred as well as clinically excellent. There is less evidence that this rhetoric has translated into measurable recommendations for the design and delivery of ANC.

Within this overall finding, there are some notable observations in the data. The lack of any national guideline at all two of the 11 countries included (Croatia, Slovakia) is a cause for some concern. This implies that, in these countries, ANC practices are left to local stakeholders to determine, which could potentially undermine the provision of high quality evidence-based practice. In two countries (Spain and Belgium) the recommendations were solely on clinical care, which differs 
from the general movement in other countries towards the inclusion of supportive and informational recommendations. Indeed, much of the absence of similarity between the WHO and the Belgian recommendations is due to the focus in the latter case on tests to perform in pregnancy, that mostly do not relate to the areas of interest of the WHO ANC guideline.

It was notable that the only recommendation that was present in all the included guidelines was related to HIV. Given the low prevalence of HIV in the European population, this is an intriguing finding. It suggests that the strong push for HIV identification and treatment that occurred in the 1980's has left a legacy on European ANC, while the changing evidence base around other more commonly applicable aspects of ANC has resulted in more variation. Given that the production of regularly updated systematic reviews of evidence should, in theory, result in increasing alignment of guidelines between countries, this finding is somewhat paradoxical.

Even in the countries most aligned to the WHO guideline, less than $50 \%$ of the global recommendations are included in national guidelines. This is at least partly explained by the fact that many of the WHO recommendations are targeted at low-income countries with particular demographics and disease profiles, resulting in recommendations that are not relevant for the majority of healthy women and babies in most high-income European countries. However, it is important to note that, even in these countries, increasing levels of migration could mean that some of these missing recommendations are relevant for some migrant women now living in Europe. These women are those that tend to have worst perinatal outcomes ${ }^{28,29}$ and poor attendance to antenatal appointments ${ }^{30}$. It is important, therefore, for European obstetricians, midwives, and service providers to be aware of the WHO recommendations that might be relevant for these specific population groups.

Overall, most of the included guidelines displayed a general concern with maximising the physiology of pregnancy, (and models of care that promote this outcome, such as continuity of care and midwife models) and to minimise the use of technical monitoring and interventions, such as ultrasound and doppler scanning. However, implementation of these precautionary principles in practice seems to be less certain. In Italy, for instance, there are large regional variations in the content and quality of the ANC pathway ${ }^{31,32}$ and continuity and midwifery models are rarely available to women. Use of ultrasound scanning is increasing globally, with rising concerns about the risks of depending on this technology to the exclusion of other aspects of $\mathrm{ANC}^{33}$. Even though the vast majority of stillborn babies die in the antenatal period, techniques designed to diagnose fetal risk have low sensitivity and specificity: in the most recent large multicentre RCT in this area, scanning and diagnostic responses, coupled with early induction, did not reduce stillbirth, but did increase iatrogenic interventions ${ }^{34}$. 
Even when guidelines are based on best evidence, the underlying trials that form the systematic reviews for this evidence may not have asked the right questions, or tested the right interventions, or measured the right outcomes. Specifically, as noted for the Danish guideline, and as found in the WHO guideline development process, measures of women's experiences, values and views are rarely included in trials, and service users are rarely asked what kinds of care they would like to be tested. The notion of 'asking different questions' in maternity care has recently been a topic of global debate ${ }^{35}$.

For the first time, this paper provides an overview of the nature of ANC guidelines for a range of European countries. It illustrates that there is large variation in what is recommended, despite access to similar evidence base for the guideline development groups. It suggests that there is still work to be done in terms of the kind of questions asked in research in this area; the kinds of outcomes that are seen as important; the constitution of the stakeholder group that is brought together to draw up and agree the guidelines; the degree to which formal, measurable recommendations go beyond clinical surveillance and treatment; and the degree to which recommendations are enacted in practice. To ensure the best outcomes for mothers, babies, families and societies in both the short and the longer term, these matters need to be addressed by national ministers of health, health care funders and providers, midwives, obstetricians and women, their families, and their wider communities.

\section{Conclusions}

This mapping review of national ANC guidelines from 11 European countries has demonstrated that some countries do not see the need for national agreement on what should be recommended for all women in terms of antenatal care. Even in the eight countries where such guidelines do exist, the only aspect which is included in the same way in every guideline relates to HIV, which is an uncommon infection in European women. However, in most included guidelines, there was evidence of a shift towards national valuation of what WHO has recently termed a 'positive pregnancy experience'. This places women's views and experiences alongside recommended clinical practices and treatments. In parallel, in a few countries there is evidence that the stakeholder group that contributes to guideline production includes some service users, and that this could be having an influence on the language used, and the scope of practice and models of care recommended However, it is not clear that these changes in philosophy of care at the ideal practice' level are being translated into general ANC provision. In addition, the kind of evidence that contributes to the systematic reviews that underpin clinical guidelines does not always ask the kinds of questions that matter to women, or measure the outcomes they are concerned about. These are matters for action by national governments, the research community, funders, practitioners, and 
service users, to maximise the effectiveness of future ANC guidelines at the national and the global level.

\section{NOTES}

\section{Conflicts of interest}

The authors certify that there is no conflict of interest with any financial organization regarding the material discussed in the manuscript.

\section{Funding}

No funding was received for the current work.

\section{Authors' contributions}

LI, SD and JC developed the project; SD and DRB focused on the background information, LI and LB created the tool for data collection, all co-authors inserted data on the tool for data collection. LI, LB, JC, conducted the data analysis supervised by SD. All co-authors contributed to discussion. JC contributed in particular to collection, analysis and discussion of data from countries without national guidelines or with outsider situations. LI assembled the paper with all the co-authors' contributions under the supervision of SD.

\section{Acknowledgments}

We would like to thank Denise Boulter (midwife consultant, Public Health Agency, Northern Ireland); Danica Lepojevik (doula, psychologist, breastfeeding counsellor and yoga instructor, Republic of Macedonia); Daniela Drandic (Head of Reproductive Rights Program at RODA Parents in Action user group, Croatia); Zuzana Kriskova (Project coordinator-Zenske kruhy, Slovakia) for all the support offered by providing and revising background information on their countries. 
This paper contributes to the EU COST Action IS1405: BIRTH: "Building Intrapartum Research Through Health - an interdisciplinary whole system approach to understanding and contextualising physiological labour and birth" (http://www.cost.eu/COST_Actions/isch/IS1405), supported by COST (European Cooperation in Science and Technology).

It also contributes to the National project: "Filosofía del Nacimiento: Repensar el Origen desde las Humanidades Médicas”, ref. FFI2016-77755-R.

\section{REFERENCES}

1. Ehrenreich B, English D. For her own good: Two centuries of the experts' advice to women. Anchor; 2005.

2. United States Children's Bureau. Prenatal Care. Washington, U. S. Govt. Print. off.; 1943.

3. Palomar-Ruiz L, Escuriet Peiró R, Ruiz-Berdún D. La obsesión por un bebé sano: la higiene del embarazo en España a lo largo del siglo XX. In: Ruiz-Berdún D, editor. Ciencia y Técnica en la Universidad. Alcalá de Henares: Universidad de Alcalá y Sociedad Española de Historia de las Ciencias y de las Técnicas; 2018. p. 79-90.

4. Enkin M, Keirse MJNC, Chalmers I, Enkin E. A guide to effective care in pregnancy and childbirth. 1989;

5. Group E-BMW. Evidence-based medicine. A new approach to teaching the practice of medicine. Jama. 1992;268(17):2420.

6. Downe S, Finlayson K, Walsh D, Lavender T. "Weighing up and balancing out": A metasynthesis of barriers to antenatal care for marginalised women in high-income countries. BJOG An Int J Obstet Gynaecol. 2009;116(4):518-29.

7. Finlayson K, Downe S. Why do women not use antenatal services in low-and middle-income countries? A meta-synthesis of qualitative studies. PLoS Med. 2013;10(1):e1001373.

8. World Health Organization (WHO). WHO recommendations on antenatal care for a positive pregnancy experience WHO Library Cataloguing-in-Publication Data WHO recommendations on antenatal care for a positive pregnancy experience. Vol. 10, World Health Organization. 2016.

9. Sackett DL, Rosenberg WMC, Gray JAM, Haynes RB, Richardson WS. Evidence based medicine: what it is and what it isn't. British Medical Journal Publishing Group; 1996. 
10. Downe S, Finlayson K, Tuncalp Ö, Metin Gülmezoglu A. What matters to women: a systematic scoping review to identify the processes and outcomes of antenatal care provision that are important to healthy pregnant women. BJOG An Int J Obstet Gynaecol. 2016;123(4):529-39.

11. EU Birth Research Project. A COST Action website detailing research into birth practices COST Action IS1405 [Internet]. Available from: https://eubirthresearch.eu/

12. Sistema Nazionale Linee Guida. Gravidanza Fisiologica. Roma; 2011.

13. Ministerio de Sanidad. Guía de Práctica Clínica sobre la Atención al Parto Normal [Internet]. Internet. 2014. 37 p. Available from:

http://www.guiasalud.es/GPC/GPC_472_Parto_Normal_Osteba_compl.pdf

14. Public Health Agency Northern Ireland Practice \& Education Council for Midwifery and Nursing. Northern Ireland Health and Social Care Maternity Services- Core Pathway for Antenatal Care. 2016;(May).

15. National Institute for Health and Care Excellence. Antenatal care [Internet]. NICE clinical guideline 62. 2008. Available from: https://www.nice.org.uk/guidance/cg62

16. Pratique RDEB. Suivi et orientation des femmes enceintes en fonction des situations à risque identifiées. 2016; Available from: http://www.has-sante.fr/portail/jcms/c_547976/fr/suivi-etorientation-des-femmes-enceintes-en-fonction-des-situations-a-risque-identifiees

17. Sundhedsstyrelsen. Anbefalinger for svangreomsorgen 2013. Sundhedsstyrelsen. 2013. Kap. $2,5,6$.

18. Rapport KCE. Welke onderzoeken zijn aanbevolen bij een zwangerschap? 2015. 2015;

19. Koninklijke Nederlandse Organisatie van Verloskundigen. Overzicht van alle richtlijnen [Internet]. 2013. Available from: https://www.knov.nl/vakkennis-enwetenschap/tekstpagina/37-2/overzicht-van-alle-richtlijnen/hoofdstuk/247/overzicht-vanalle-richtlijnen/

20. Nederlandse Vereniging voor Obstetrie \& Gynaecologie. Richtlijnen Perinatologie [Internet]. 2018. Available from:

https://www.nvog.nl/kwaliteitsdocumenten/richtlijnen/perinatologie/\%0A

21. Commissie Verloskunde van het College voor zorgverzekeringen. Verloskundig vademecum 2003 [Internet]. 2003. Available from: https://www.knov.nl/vakkennis-enwetenschap/tekstpagina/524-2/verloskundige-indicatielijst/hoofdstuk/733/verloskundigeindicatielijst/

22. Australian Health Ministers' Advisory Council. Clinical Practice Guidelines: Antenatal Care - Module II [Internet]. Australian Government Department of Health and Ageing. 2015. Available from: http://www.health.gov.au/antenatal

23. National Institute for Health and Care Excellence. Antenatal care for uncomplicated pregnancies: schedule of appointments. 2014;

24. Healy M, Gillen P. Planning birth in and admission to a midwife-led unit: development of a 
GAIN evidence-based guideline. Evidence Based Midwifery. 2016 14(3): 82-86;

25. Guidelines and Audit Implementation Network (GAIN). Guideline for admission to midwifeled units in Northern Ireland and Northern Ireland Normal Labour and Birth Care Pathway. Belfast. RQIA. 2016. Available from: https://www.rqia.org.uk/RQIA/files/3a/3a7a37bbd601-4daf-a902-6b60e5fa58c2.pdf

26. National Institute for Health and Care Excellence. Antenatal and postnatal mental health: clinical management and service guidance CG45. London: National Institute for Health \& Clinical Excellence; 2007.

27. Kuhnt J, Vollmer S. Antenatal care services and its implications for vital and health outcomes of children: evidence from 193 surveys in 69 low-income and middle-income countries. BMJ Open. 2017;7(11):e017122.

28. Kramer MS, Seguin L, Lydon J, Goulet L. Socio-economic disparities in pregnancy outcome: why do the poor fare so poorly? Paediatr Perinat Epidemiol. 2000;14(3):194-210.

29. Gavin AR, Nurius P, Logan-Greene P. Mediators of adverse birth outcomes among socially disadvantaged women. J Women's Heal. 2012;21(6):634-42.

30. Gibson-Helm M, Boyle J, Cheng I, East C, Knight M, Teede H. Maternal health and pregnancy outcomes among women of refugee background from Asian countries. Int J Gynecol Obstet. 2015;129(2):146-51.

31. Basili F, Di Rosa A, Montorio V, Tamburini C. Certificato di assistenza al parto (CeDAP). Analisi dell'evento nascita - Anno 2011 [Internet]. Ministero della Salute. 2014. Available from:

http://www.salute.gov.it/imgs/C_17_pubblicazioni_1551_allegato.pdf\%5Cnpapers2://publica tion/uuid/D9792949-B87C-4E94-AC44-E832266079D7

32. Lauria L, Lamberti A, Buoncristiano M. Percorso nascita:promozione e valutazione della qualità di modelli operativi. Le indagini del 2008-2009 e del 2010-2011. 2012.

33. O'Keeffe DF, Abuhamad A. Obstetric ultrasound utilization in the United States: data from various health plans. In: Seminars in perinatology. Elsevier; 2013. p. 292-4.

34. Grobman WA, Rice MM, Reddy UM, Tita ATN, Silver RM, Mallett G, et al. Labor Induction versus Expectant Management in Low-Risk Nulliparous Women. N Engl J Med [Internet]. 2018 Aug 8;379(6):513-23. Available from: https://doi.org/10.1056/NEJMoa1800566

35. Kennedy HP, Cheyney M, Dahlen HG, Downe S, Foureur MJ, Homer CSE, et al. Asking different questions: A call to action for research to improve the quality of care for every woman, every child. Birth. 2018; 


\begin{tabular}{|c|c|c|c|}
\hline UNITED KINGDOM & $\begin{array}{l}\text { National Institute for Clinical } \\
\text { Excellence -NICE }\end{array}$ & Antenatal Care for Uncomplicated Pregnancies & 2008 last update in 2017 \\
\hline DENMARK & $\begin{array}{c}\text { Komiteen for Sundhedsoplysning } \\
\text { (Committee on Health } \\
\text { Information) }\end{array}$ & $\begin{array}{l}\text { Anbefalinter for svangreomsrogen } \\
\text { (Recommendations for antenatal care) }\end{array}$ & 2013 \\
\hline
\end{tabular}

\section{TABLES}




\begin{tabular}{|c|c|c|c|}
\hline & & under the Law of Health Protection) & \\
\hline SPAIN & $\begin{array}{c}\text { Ministerio De Sanidad, Servicios } \\
\text { Sociales E Igualdad } \\
\text { (Ministry of Health, Social } \\
\text { Services and Equality) }\end{array}$ & $\begin{array}{c}\text { Guía de práctica clinica de atención en el embarazo y } \\
\text { puerperio } \\
\text { (Pregnancy and postnatal care guidelines) }\end{array}$ & 2014 \\
\hline BELGIUM & $\begin{array}{l}\text { Federaal Kenniscentrum voor de } \\
\text { Gezondheidszorg } \\
\text { KCE (Belgian Health Care } \\
\text { Knowledge Centre) }\end{array}$ & $\begin{array}{l}\text { Welke onderzoeken zijn aanbevolen bij een } \\
\text { zwangerschap? } \\
\text { What tests are recommended during pregnancy? }\end{array}$ & 2015 \\
\hline FRANCE & $\begin{array}{l}\text { Haute Autorité de Santé } \\
\text { (High Authority of Health) }\end{array}$ & $\begin{array}{c}\text { Suivi et orientation des femmes enceintes en function } \\
\text { des situations à risque identifiées } \\
\text { (Monitoring And Orientation Of Pregnant Women } \\
\text { Based On Identified Risk Situations) }\end{array}$ & 2016 \\
\hline NORTHERN IRELAND & $\begin{array}{l}\text { Health and Social Care board } \\
\text { Public Health Agency }\end{array}$ & Core Pathway for Antenatal Care & 2016 \\
\hline WHO & WHO & $\begin{array}{l}\text { WHO recommendations on antenatal care for a positive } \\
\text { pregnancy experience }\end{array}$ & 2016 \\
\hline
\end{tabular}

Table I: Summary of the guidelines considered, ordered per year of publication.

Table II: Main areas of interests of recommendations in WHO guidelines on ANC. 


\section{NUTRITIONAL INTERVENTIONS}

\section{MATERNAL AND FETAL ASSESSMENT}

FETAL ASSESSMENT

PREVENTIVE MEASURES

INTERVENTIONS FOR COMMON

PHYSIOLOGICAL SYMPTOMS

\section{HEALTH SYSTEMS INTERVENTIONS}

TO IMPROVE THE UTILIZATION AND

QUALITY OF ANTENATAL CARE
- Dietary interventions

- Iron and folic acid supplements

- Calcium supplements

- Vitamin A supplements

- Zinc supplements

- Multiple micronutrient supplements

- Vitamin B6 (pyridoxine) supplements

- Vitamin E and C supplements

- Vitamin D supplements

- $\quad$ Restricting caffeine intake

- Anaemia

- $\quad$ Asymptomatic bacteriuria (ASB)

- $\quad$ Intimate partner violence (IPV)

- Gestational diabetes mellitus (GDM)

- Tobacco use

- Substance use

- Human immuno-deficiency virus (HIV) and syphilis

- Tuberculosis (TB)

- $\quad$ Daily fetal movement counting

- $\quad$ Symphysis-fundal height (SFH) measurement

- Antenatal cardio-tocography

- Ultrasound scan

- Doppler ultrasound of fetal blood vessels

- $\quad$ Antibiotics for asymptomatic bacteriuria (ASB)

- Antibiotic prophylaxis to prevent recurrent urinary tract infections

- Antenatal anti-D immunoglobulin administration

- Preventive anthelminthic treatment

- Tetanus toxoid vaccination

- Malaria prevention: intermittent preventive treatment in pregnancy (IPTp)

- $\quad$ Pre-exposure prophylaxis (PrEP) for HIV prevention

- $\quad$ Nausea and vomiting

- Heartburn

- $\quad$ Leg cramps

- $\quad$ Low back and pelvic pain

- Constipation

- Varicose veins and oedema

- Woman-held case notes

- $\quad$ Midwife-led continuity of care

- Group antenatal care

- Community-based interventions to improve communication and support

- Task shifting components of antenatal care delivery

- Recruitment and retention of staff in rural and remote areas

- Antenatal care contact schedules

\section{FIGURES}


Figure 1: Example of the coding of European recommendations in comparison with the WHO recommendations. Snapshot from the dataset sheets.

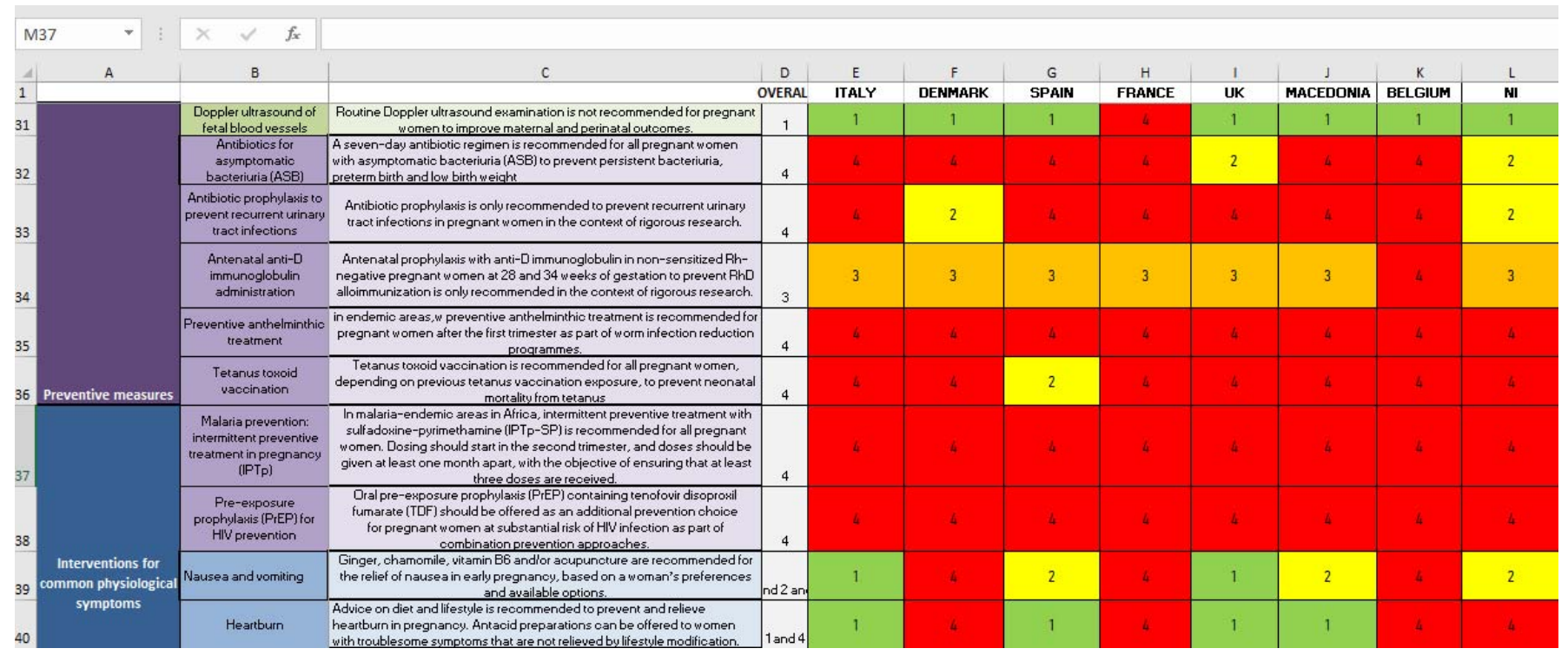

